\title{
Fractional Order and BICO Disturbance Observers for a Run-of-Mine Ore Milling Circuit ${ }^{\sqrt{3}}$
}

\author{
L.E. Olivier ${ }^{\mathrm{a}}$, I.K. Craig, ${ }^{\mathrm{a}, *}$, Y.Q. Chen ${ }^{\mathrm{b}}$ \\ ${ }^{a}$ Department of Electrical, Electronic, and Computer Engineering, University of \\ Pretoria, Pretoria, South Africa. \\ ${ }^{b}$ CSOIS, Electrical and Computer Engineering Department, Utah State University, \\ Logan, USA.
}

\begin{abstract}
Grinding mill circuits are hard to control due to poor plant models, large external disturbances, uncertainties from internal couplings, and process variables that are difficult to measure. This paper proposes a novel fractional order disturbance observer (FO-DOB) for a run-of-mine (ROM) ore milling circuit. A fractional order low pass filter $(Q$-filer $)$ is used in the DOB to offer an additional degree of freedom in tuning for set-point tracking performance and disturbance rejection performance. Another disturbance observer is introduced in which a Bode ideal cut-off (BICO) filter is used for the $Q$ filter. A full non-linear plant model is used for evaluation of the performance gained over the ubiquitous PI controller. The simulation results show that the FO-DOB and BICO-DOB schemes are useful additional tools for ROM ore milling circuit control implementations.
\end{abstract}

\footnotetext{
A preliminary version of this article was presented at the IEEE Africon Conference, Zambia 2011.

${ }^{*}$ Corresponding author. Address: Department of Electrical, Electronic, and Computer Engineering, University of Pretoria, Pretoria, South Africa.

Tel.: +27 12420 2172; fax: +27 123625000 .

Email address: icraig@postino.up.ac.za (I.K. Craig)
} 


\section{Keywords:}

Bode ideal cut-off, disturbance observer, fractional order, milling, run-of-mine ore

\section{Introduction}

Milling ore down to a fine product is usually the first step in any metallurgical extraction process [1]. The product of the milling circuit is passed downstream to some separation process such as leaching or flotation. Optimizing the milling circuit performance is therefore important as consistent material should be passed to the downstream process.

ROM ore milling circuits are generally difficult to control due to the presence of strong external disturbances, poor plant models, and process variables that are difficult to measure [2]. Currently PID control is the most common control technology used in milling circuits [3]. This is different in general from the process industries where model predictive control (MPC) is the most common [4]. This might be attributed to the fact that PID control is much easier to understand and maintain than an advanced control method such as MPC, even though the advantages of using MPC over PID in grinding circuit control is well documented (see for instance [5]). MPC does however struggle to produce good results in the presence of strong external disturbances and severe model-plant mismatch [6].

Disturbance observer (DOB) based control helps to compensate for modelplant mismatch and external disturbances, both of which are common in ROM ore milling circuit control. A DOB has already been applied to a grinding mill circuit [6] with good results. The main contribution of this 
article is the presentation of the application of a fractional order disturbance observer (FO-DOB) to the ROM ore milling circuit, as well as the introduction of a novel Bode ideal cut-off disturbance observer (BICO-DOB) and the application thereof in the control of the milling circuit. These make use of a fractional order $Q$-filter and a BICO $Q$-filter respectively. This offers additional tuning freedom to optimize performance in the presence of strong external disturbances and severe model-plant mismatch. These disturbance observers are implemented in conjunction with a standard PI controller to show how these schemes may improve controller performance.

\section{Description of the ROM Ore Milling Circuit}

A brief process description is provided here, similar to that given in [7].

Gold-bearing ore is fed to the milling circuit at about $100 \mathrm{t} / \mathrm{h}$. The ore is ground down to product with a particle size of $80 \%$ smaller than $75 \mu \mathrm{m}$ $\left(P_{80}=75 \mu \mathrm{m}\right)$. A hydrocyclone is used in closed circuit with the mill to separate the product from the out-of-specification material. The gold is then extracted through a leaching process downstream.

The feed to the mill (see Fig. 1) is constituted of the underflow of the cyclone, feed ore, water and steel balls. Steel balls are usually added in discrete quantities by the operator but in this study it will be treated as a continuous variable. The mill discharges the ground slurry into a sump through an end-discharge grate. The slurry is diluted with water in the sump and pumped to the hydrocyclone for classification. The product of the milling circuit is the overflow of the hydrocyclone.

The controlled variables in the milling circuit are the product particle 


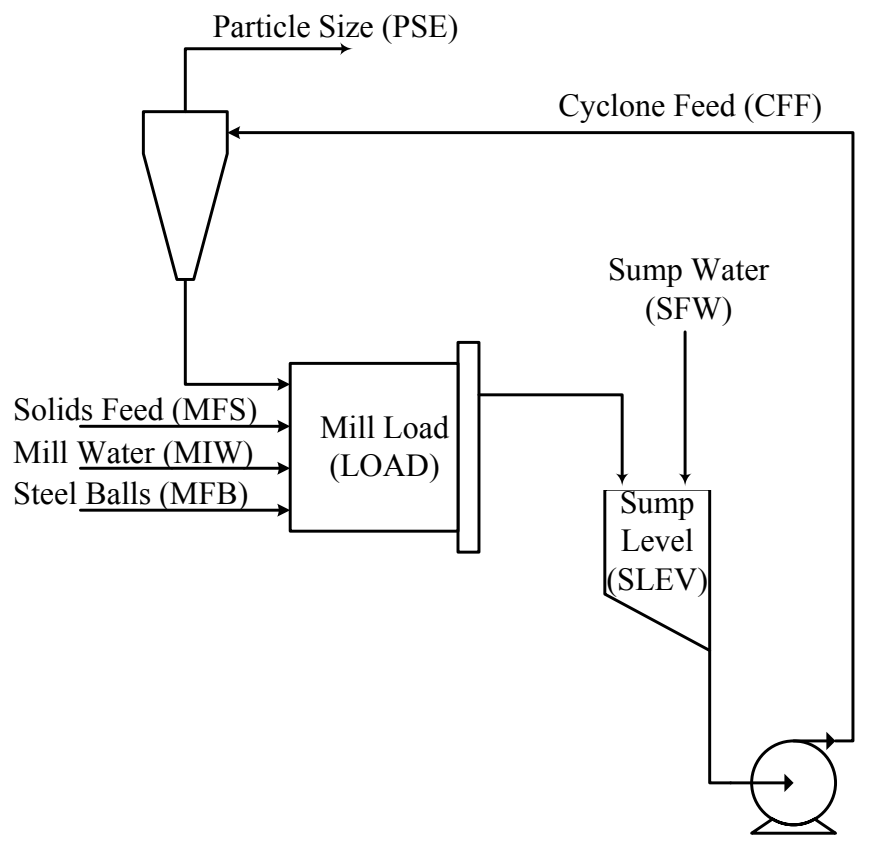

Figure 1: ROM ore milling circuit

size (PSE), the fraction of the mill volume filled with material (LOAD), and the volume of slurry in the sump (SLEV). The manipulated variables are the feed-rate of solids into the mill (MFS), the feed-rate of water into the mill (MIW), the feed-rate of steel balls into the mill (MFB), the flow-rate of water into the sump (SFW), and the flow-rate of slurry into the cyclone $(\mathrm{CFF})$. The operating point of the milling circuit variables and constraints on these variables are based on [8] and given in Table 1.

The milling circuit model consists of separate modules for the feeder, mill, sump and hydrocyclone. The model uses five states, namely water, rocks, solids, fines, and steel balls to describe the flow of material through the milling circuit. All the equations that constitute the non-linear model are based on these material classifications. A full description of these equations 
Table 1: Constraints and operating point

\begin{tabular}{|c|c|c|c|c|}
\hline Variable & Min & Max & $\mathrm{OP}$ & Description \\
\hline MIW & 0 & 100 & 33.33 & $\begin{array}{l}\text { Flow-rate of } \\
\text { water to the } \\
\text { mill }\left[\frac{\mathrm{m}^{3}}{\mathrm{~h}}\right]\end{array}$ \\
\hline MFS & 0 & 200 & 100 & $\begin{array}{l}\text { Flow-rate of } \\
\text { solids to the } \\
\text { mill }\left[\frac{\mathrm{t}}{\mathrm{h}}\right]\end{array}$ \\
\hline MFB & 0 & 4 & 2 & $\begin{array}{l}\text { Flow-rate of } \\
\text { steel balls to } \\
\text { the mill }\left[\frac{\mathrm{t}}{\mathrm{h}}\right]\end{array}$ \\
\hline $\mathrm{CFF}$ & 400 & 500 & 442 & $\begin{array}{l}\text { Flow-rate of } \\
\text { slurry to the } \\
\text { cyclone }\left[\frac{\mathrm{m}^{3}}{\mathrm{~h}}\right]\end{array}$ \\
\hline SFW & 0 & 400 & 267 & $\begin{array}{l}\text { Flow-rate of } \\
\text { water to the } \\
\text { sump }\left[\frac{\mathrm{m}^{3}}{\mathrm{~h}}\right]\end{array}$ \\
\hline PSE & 60 & 90 & 80 & $\begin{array}{l}\text { Product } \\
\text { particle-size } \\
{[\%<75 \mu \mathrm{m}]}\end{array}$ \\
\hline LOAD & 30 & 50 & 45 & $\begin{array}{l}\text { Total charge of } \\
\text { the mill }[\%]\end{array}$ \\
\hline SLEV & 2 & 37.5 & 30 & $\begin{array}{l}\text { Level of the } \\
\text { sump }\left[\mathrm{m}^{3}\right]\end{array}$ \\
\hline
\end{tabular}


can be found in [8].

The main sources of non-linearity in the process are the breakage functions that describe how material change state inside the mill. The amount of fines produced in the mill is expressed as

$$
F P \triangleq \frac{P_{\text {mill }}}{D_{s} \phi_{f}\left[1+\alpha_{\phi_{f}}\left(\frac{L O A D}{v_{\operatorname{mill}}}-v_{P_{\max }}\right)\right]},
$$

where $P_{\text {mill }}$ is the mill power, $D_{s}$ is the density of feed ore, $\phi_{f}$ is the energy needed to produce a ton of fine ore, $\alpha_{\phi_{f}}$ is the fractional change in $\phi_{f}$ per change in fractional filling of the mill, $v_{\text {mill }}$ is the mill volume and $v_{P_{\max }}$ is the fraction of mill volume to be filled for maximum power usage. LOAD is the total charge of the mill given by $L O A D=X_{w}+X_{s}+X_{r}+X_{b}$ where $X_{w}, X_{s}, X_{r}$ and $X_{b}$ are respectively the hold-ups in the mill of water, solids, rocks and balls. The amount of rocks consumed in the mill is given by

$$
R C \triangleq \frac{1}{D_{s} \phi_{r}} \cdot P_{\text {mill }} \cdot \varphi \cdot\left(\frac{X_{r}}{X_{r}+X_{s}}\right),
$$

where $\phi_{r}$ is the rock abrasion factor and $\varphi$ is the rheology factor, that relates to the fluidity of slurry inside the mill, given by

$$
\varphi \triangleq \sqrt{\frac{\max \left[0,\left(X_{w}-\left(\frac{1}{\varepsilon_{w s}}-1\right) X_{s}\right)\right]}{X_{w}}},
$$

with $\varepsilon_{w s}$ the maximum water-to-solids volumetric ratio at zero slurry flow. A full description of the non-linear model is given in [8].

Two important parameters to note in the non-linear model is the fraction of rocks in the feed ore $\left(\alpha_{r}\right)$ that gives an indication of the composition of the ore and the energy needed for a ton of fines produced $\left(\phi_{f}\right)$ that gives an indication of the hardness of the feed ore. A change in either of these two 
parameters may be considered as the introduction of an external disturbance into the plant. This is because there is no control over the composition and hardness of the feed ore entering the milling circuit. These parameters will be varied in what follows to test the disturbance rejection capabilities of different controllers.

Both of these parameters, $\alpha_{r}$ and $\phi_{f}$, mainly affect the grinding performance of the mill. Because the solid ore itself also acts as grinding medium, a change in $\alpha_{r}$ implies a change in the composition of the grinding medium and a change in $\phi_{f}$ implies a change in the hardness. Grinding harder ore requires more energy and consequently a drop in throughput should the same particle size be required.

\subsection{Linearized milling circuit model}

Model based milling circuit controllers, such as linear model predictive control, and common PI(D) tuning rules require a linearized plant model. Such a linear model of the plant is obtained through applying a standard system identification (SID) procedure as described by [9], to the milling circuit model described by [8] around the operating point given in Table 1. The final linearized model for control is given by:

$$
\left[\begin{array}{c}
\triangle P S E \\
\triangle L O A D \\
\Delta S L E V
\end{array}\right]=\left[\begin{array}{lll}
g_{11} & g_{12} & g_{13} \\
g_{21} & g_{22} & g_{23} \\
g_{31} & g_{32} & g_{33}
\end{array}\right]\left[\begin{array}{c}
\Delta C F F \\
\Delta M F S \\
\Delta S F W
\end{array}\right]
$$

In (4), the transfer function elements are (with all time constants and delays in hours): 


$$
\begin{aligned}
& g_{11}=\frac{-3.63 \times 10^{-4}(-0.93 s+1)}{(0.81 s+1)(0.02 s+1)} \exp (-0.011 s) \\
& g_{12}=\frac{-0.0048}{1.02 s+1} \exp (-0.064 s) \\
& g_{13}=\frac{7.52 \times 10^{-4}}{0.60 s+1} \exp (-0.011 s) \\
& g_{21}=\frac{0.0173(7.6276 s+1)}{(1.72 s+1)(69.4 s+1)} \exp (-0.014 s) \\
& g_{22}=\frac{0.00375}{s} \\
& g_{23}=\frac{-0.0025}{5.25 s+1} \exp (-0.014 s) \\
& g_{31}=\frac{-0.5651}{s} \exp (-0.014 s) \\
& g_{32}=\frac{0.3611}{s} \\
& g_{33}=\frac{0.6119}{s}
\end{aligned}
$$

The model does not contain reference to the manipulated variables MIW and MFB. In this study the value of MFB is kept constant at its nominal value of $2[\mathrm{t} / \mathrm{h}]$. The value of MIW is derived from the value of MFS through a constant water to solids ratio into the mill as discussed in [10].

The linearized plant model (5) is only used for controller design. The simulations that follow are all based on the full non-linear model of the ROM ore milling circuit, unlike [11].

\section{PI control}

Decentralized PI control is implemented on the ROM ore milling circuit of [8] as the baseline against which all the disturbance observed based schemes will be compared. Because of the popularity of decentralized PI control for milling circuits ([3]), this study investigates how the performance of the widely applied decentralized controller may be improved simply through the addition of various disturbance observers The disturbance observer will then handle the loop interactions unaccounted for by the decentralized controller. 


\subsection{PI controller design}

Decentralized PID control is the most common approach to feedback control in multi-variable mineral processing plants [3]. Variables are usually coupled in single-input-single-output (SISO) loops [2]. Traditionally the input-

output pairings on milling circuits are $S F W \rightarrow P S E, M F S \rightarrow L O A D$, and $C F F \rightarrow S L E V([10])$. It was however found by [10] that these pairings give rise to significant couplings that cause the sump to either overflow or run dry as soon as significant ore hardness and composition disturbances were introduced.

In this study the manipulated variables are paired with the controlled variables as $C F F \rightarrow P S E, M F S \rightarrow L O A D$, and $S F W \rightarrow S L E V$ for which [10] found much better robustness to feed disturbances that result in actuators saturating. The internal model control (IMC) tuning rules as presented in $[12$, p.308] are then applied to obtain three PI controllers. Pairing variables in SISO loops and independently designing a PI controller for each is not generally the best method for decentralized controller design. Despite the drawbacks of this method, it does usually satisfy metallurgical needs if the variable pairings are well chosen ([2]) and coupled with its simplicity makes it a common choice $([3])$.

The IMC-based controller settings, as used here, explicitly specifies a PI(D) controller through analytic tuning relations such that the closed-loop response takes the form of a low-pass filter

$$
G_{c l, d}=\frac{1}{\left(\tau_{c} s+1\right)^{r}} .
$$

$G_{c l, d}$ is the desired closed-loop response, $\tau_{c}$ is the desired time constant for the response, which is specified to be 0.01 according to [10], and $r$ is the 
Table 2: Tuning parameters for PI controllers

\begin{tabular}{ccc} 
Control loop & $K_{c}$ & $\tau_{I}$ \\
\hline$C F F \rightarrow P S E$ & $2.229 \times 10^{3}$ & 0.84 \\
$M F S \rightarrow L O A D$ & $5.327 \times 10^{4}$ & 0.02 \\
$S F W \rightarrow S L E V$ & $3.269 \times 10^{2}$ & 0.02 \\
\hline
\end{tabular}

order of the response which is usually chosen to be 1 [12], as was also done here. The tuning parameters for the controllers are given in Table 2 .

These parameters are applicable to the parallel form of representing a PI controller.

\section{Disturbance observer based control}

Disturbance observers have several attractive features. In the absence of large modelling errors, DOBs allow independent tuning of disturbance rejection and command following characteristics. Furthermore, compared to integral action, disturbances observers are more flexible as they allow for the selection of the order, relative degree, and the bandwidth of the low-pass filter known as the disturbance observer filter or the $Q$-filter (see Fig. 2). Although it is known that by appending disturbance states to a traditional state estimator [13] the disturbance compensation can be easily handled, a DOB is in fact more welcomed by control practitioners because the DOB structure allows simple and intuitive tuning of the disturbance observer loop gains independent of the state feedback gains.

As pointed out in [14] and [15] there is a trade-off between the phase margin loss and the strength of low frequency attenuation when applying a 


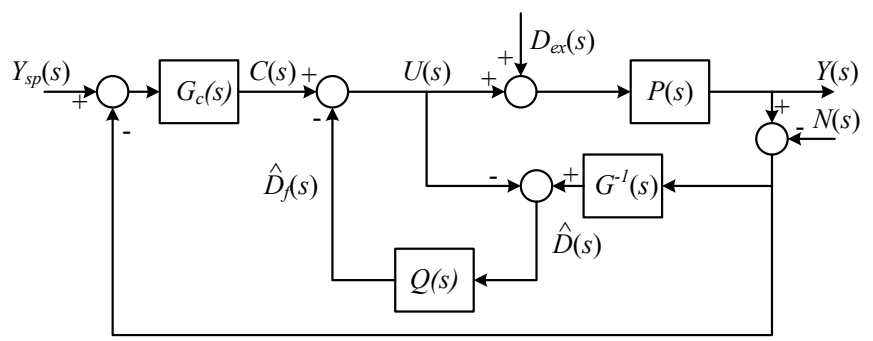

Figure 2: Block diagram of a conventional disturbance observer

DOB. Given the required cutoff frequency of the $Q$-filter, it turns out that the relative degree of the $Q$-filter is the major tuning knob for this tradeoff. As a motivation for the fractional order $Q$-filter, a solution based on an integer order $Q$-filter with variable relative degrees is introduced which is the key contribution of [16]. A fractional order disturbance observer based on the fractional order $Q$-filter is presented, similar to the filter used in [14].

A DOB in a process control context can be found in [17] for generic processes. However, for milling grinding processes, the application of a DOB presented in $[6]$ is more recent.

\subsection{Integer order disturbance observer}

The layout of a conventional disturbance observer in a control loop is presented Fig. 2. Signals $C(s), U(s), D_{e x}(s), Y(s), Y_{s p}(s)$, and $N(s)$ are the control signal, manipulated variable, external disturbance, controlled variable, set-point, and noise signal values respectively. The signals $\hat{D}(s)$ and $\hat{D}_{f}(s)$ are the estimates of the lumped disturbances before and after being filtered by the $Q$-filter. $G_{c}(s)$ is the controller, $P(s)$ is the actual plant, $G(s)$ is the nominal plant model (as shown in (5)) and $Q(s)$ is the $Q$-filter.

The $Q$-filter is designed to be in the form of a low-pass filter such that the 
estimate of the lumped disturbance approximately equals the actual lumped disturbance in the low-frequency range, and that noise be filtered out in the high frequency range [6].

The inverse of the nominal plant model $\left(G^{-1}\right)$ is usually not realizable [18]. This is due to the inverse of the nominal model usually having more zeros than poles, and the predictor element resulting from taking the inverse of a time delay that is usually present in the original model. In order to make the disturbance observer realizable, two techniques are employed. Firstly the model elements to be inverted are factored as

$$
G_{i i}=G_{+} G_{-}
$$

$G_{i i}$ contains only the diagonal elements of $G$, and only these elements need to be inverted such that the lumped disturbance estimate will contain the uncompensated coupling effects as shown in [6]. $G_{+}$contains any time delays and right-half plane zeros and is required to have a steady-state gain equal to 1 to ensure that the two factors in (7) are unique. This is similar to what is done when designing an IMC controller [12]. Only the minimum phase component of the model $\left(G_{-}\right)$is then inverted.

Secondly the layout of the DOB is modified such that the inverse of the minimum-phase component of the plant is cascaded with the $Q$-filter. The $Q$-filter is then specified with a minimum order based on the relative order of the plant model. The modified disturbance observer is shown in Fig. 3.

These modifications do imply that only $G_{-}$is now used as the effective plant model as opposed to $G$. $G_{-}$therefore becomes the model that the disturbance observer wants to maintain and any difference between $G_{-}$and 


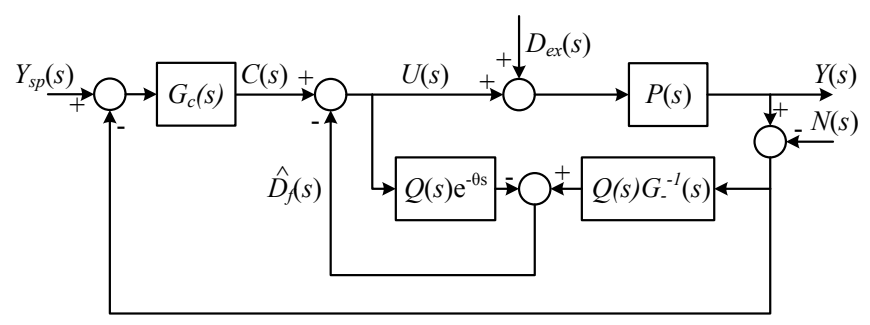

Figure 3: Block diagram of the modified disturbance observer

the actual plant $P$, as will inherently be present, will be lumped together with the estimate of the external disturbances. This is derived in [6] and shown later in this section. It does mean that the disturbance estimate is not only of the external disturbances, as shown in (9), but is advantageous for controller performance.

The design of the DOB is independent of the design of the controller and thus the same PI controller as discussed in section 3.1 can be used as the feedback controller for the disturbance observer based control. Because this plant is presented by a 3 -input, 3-output model the $Q$-filter is specified as a $3 \times 3$ matrix with diagonal elements of the form

$$
Q_{i i}=\left(\frac{1}{\lambda_{i i} s+1}\right)^{n}
$$

where $\lambda_{i i}$ determines the filter bandwidth and $n$ is the filter order $(n \in \mathbb{N})$. Based on the model presented in Sec. 2.1 the order of the $Q$-filter should be at least 2 such that the cascaded transfer function $Q(s) G_{-}^{-1}(s)$ is realizable.

It is shown in $[6]$ that the lumped disturbance estimate $(\hat{D}(s))$ given by the disturbance observer is 


$$
\hat{D}(s)=\hat{D}_{e x}(s)+\hat{D}_{m}(s)+\hat{D}_{c}(s)
$$

where $D_{e x}(s)$ is the external disturbance, $D_{m}(s)$ is the internal disturbance caused by model-plant mismatches and $D_{c}(s)$ is the internal disturbance caused by unconsidered coupling effects. This is an interesting result because it shows that the disturbance observer will also help counter the effects of model-plant mismatch and unconsidered coupling effects. It therefore implies that even without any external disturbances or model-plant mismatch, the DOB will improve the set-point tracking performance of a diagonal PI(D) controller when applied to a inherently multivariable plant.

\subsection{Fractional order disturbance observer}

The concept of a FO-DOB was first proposed in [14] in a motion control context and experimentally validated in [19].

The two tuning parameters in the DOB $Q$-filter is the filter bandwidth and the filter order. Not limiting the filter order to the set of integers would therefore be a valuable aid in tuning such that the optimal filter order may be implemented. The concept of the fractional order disturbance observer is to represent the diagonal elements of the filter transfer function as

$$
Q_{i i}=\left(\frac{1}{\lambda_{i i} s+1}\right)^{\alpha}
$$

where $\alpha \in \mathbb{R}$. Details of how the fractional order low-pass filter is realized is given in Appendix A. Because the filter order is now not restricted to be an integer, an optimal value for the filter order may be specified based on the desired performance. 
To determine the optimal filter order, disturbances were introduced into the system and set-point changes were made in the presence of model-plant mismatch. The simulation conditions are as described in Section 5. The disturbances introduced here are changes in the fraction of rocks in the feed ore $\left(\alpha_{r}\right)$ and the amount of energy needed per ton of fines produced $\left(\phi_{f}\right)$. The former is an indication of the composition of the feed ore while the latter is an indication of the hardness of the ore. The ISE (integral squared error) values (normalized to be between 0 and 1 ) are shown in Fig. 4. The ISE will depend on the type of perturbation used e.g. a step or a ramp. A step perturbation in the parameter values could occur in practice when the ore feed is switched to come from a different stockpile.

The feed variations in the run-of-mine ore can introduce other forms of disturbances as well, such as those that arise from pile formation and reclaiming procedures that result in material segregation. Such drifting disturbances are however easier to deal with by the DOB than the step disturbances used in this study.

From Fig. 4 it is clear that smaller filter order values give better disturbance rejection performance. This is the same result that was found for linear models in [11]. It is interesting to note that the normalized ISE values for set-point tracking is not monotonic. For filter orders slightly larger than 2 a minimum is achieved before the ISE values increase to a maximum at order equal to 2.5 before decreasing again as the filter order increases. This behaviour is not the same as was found for linear models in [11]. The difference between the result obtained here and that obtained in [11] is that the non-linear plant model is used here. This non-monotonicity is also only 


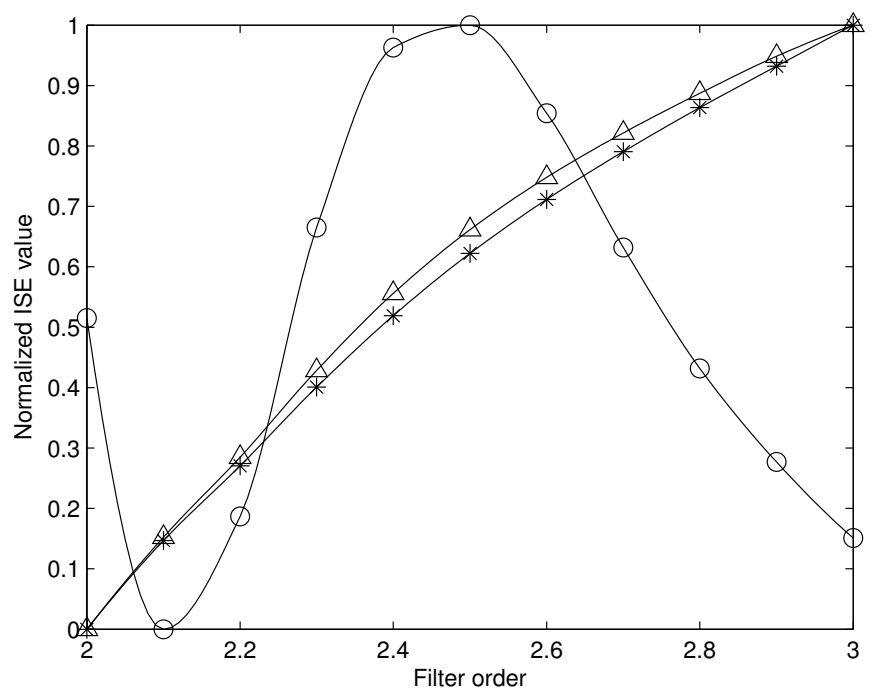

Figure 4: Normalized ISE values for different filter orders for $\alpha_{r}$ disturbance (*-markers), $\phi_{f}$ disturbance $(\triangle$-markers) and set-point change $(\bigcirc$-markers).

seen for the set-point change where the plant changes operating point. This seems to indicate that there is no general rule for predicting the ISE values obtained from the non-linear simulation. When the filter order increases to above 3 the normalized ISE values once again increase monotonically.

In order to determine the filter order that achieves the best combined performance the objective function

$$
J=\gamma \sum_{1}^{M} \frac{1}{M} I S E_{s p, M}+(1-\gamma) \sum_{1}^{N} \frac{1}{N} I S E_{d, N}
$$

should be minimized with respect to the disturbance observer filter order. In $(11), \gamma$ is a weight in $(0,1)$ that determines whether the emphasis is on disturbance rejection or set-point tracking, $I S E_{s p, M}$ and $I S E_{d, N}$ are the normalized ISE values for set-point tracking and disturbance rejection respectively, $M$ is the number of different set-point changes to consider and $N$ is the num- 
ber of different disturbances under study. Practically the value of $M$ should indicate the number of all common set-point changes. This value may be irrelevant if only disturbance rejection is of concern. $N$ should indicate the number of all common and foreseeable disturbances that significantly affect the plant.

Setting $\gamma=0.5$ (equal weight on set-point tracking and disturbance rejection) the objective function gives the optimal filter order to be 2.1. Placing more importance on disturbance rejection than set-point tracking will reduce the optimal filter order. Because the optimal filter order is already quite close to that of the integer order DOB, $\gamma=0.5$ is sufficient here for comparison purposes. The FO-DOB is therefore implemented with a $Q$-filter of order 2.1. The controller used is again the same PI-controller discussed in Sec. 3.1.

Calculating $J$ according to (11) with the values as shown in Fig. 4 gives $J=0.0583$ for the FO-DOB as opposed to $J=0.2575$ for the integer order DOB. This suggests that there would be an improvement in overall performance with the FO-DOB implementation when considering set-point tracking and disturbance rejection.

\subsection{Bode ideal cut-off disturbance observer}

Bode introduced the ideal cut-off filter in [20] such that the filter would produce an optimal trade-off between the desired phase margin and the most rapid cut-off. The transfer function of the filter is given by

$$
\beta(s)=\frac{K}{\left(\sqrt{1+\frac{s^{2}}{\omega_{o}^{2}}}+\frac{s}{\omega_{o}}\right)^{2(1-\eta)}}
$$



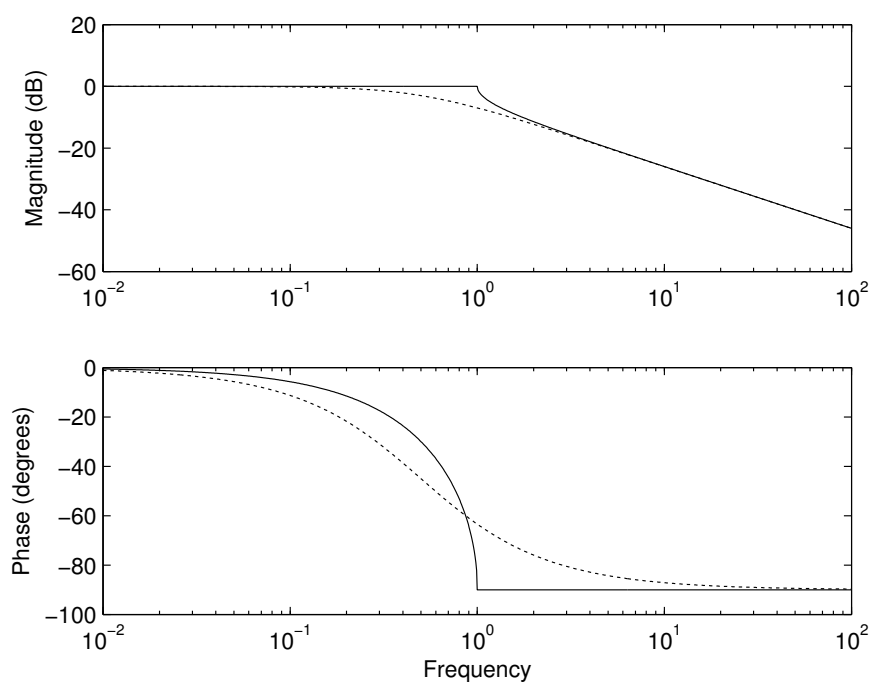

Figure 5: Bode plot of a BICO filter (solid line) and a regular first-order filter (dotted line).

where $\omega_{o}$ is the cut-off frequency and $\eta$ is a parameter relating to the filter order such that the roll-off at frequencies much larger than $\omega_{o}$ be $-40(1-$

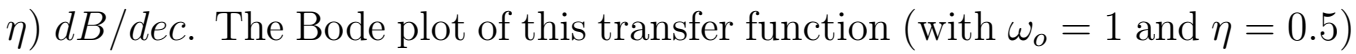
is shown in Fig. 5. The response of a first-order filter as given by (8) is also indicated in the figure.

It is notable from Fig. 5 that the BICO filter has a flat amplitude response in the pass-band of the filter and then a rapid cut-off. The phase of the BICO filter is approximately constant in the stop-band which means that the phase margin would be relatively insensitive to uncertainties.

Details of how the BICO filter may be implemented are given in Appendix B.

For the BICO filter the two tuning parameters are $\omega_{o}$ and $\eta$. These parameter values are also determined through simulating different combina- 


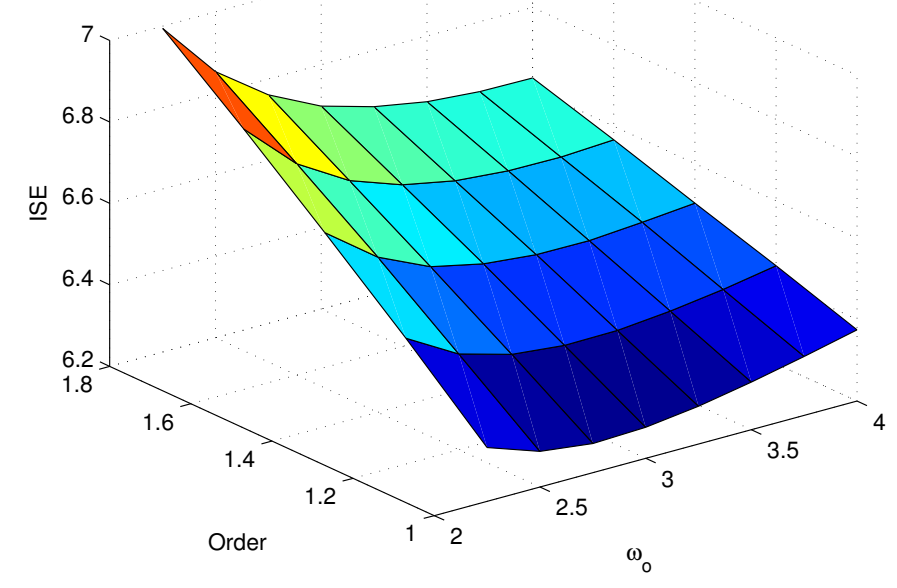

Figure 6: ISE values obtained with different filter bandwidth and filter order values for the BICO-DOB.

tions and calculating the parameter values that produce the optimal overall performance. This procedure is similar to that discussed in Sec. 4.2 for the FO-DOB. Fig. 6 shows the ISE values obtained for different filter order and bandwidth values. The optimal value is achieved for $\omega_{o}=2.75$ and $n=1$. The relative order $n=1$ is equivalent to $\eta=0.5$ in equation (12).

\section{Simulation Results}

The PI controller discussed in Sec. 3 as well as the three disturbance observers (as discussed in Sec. 4) are implemented on the non-linear model of the ROM ore milling circuit. The external disturbance rejection capabilities of each as well as the set-point tracking capabilities are tested and the results are presented here. 


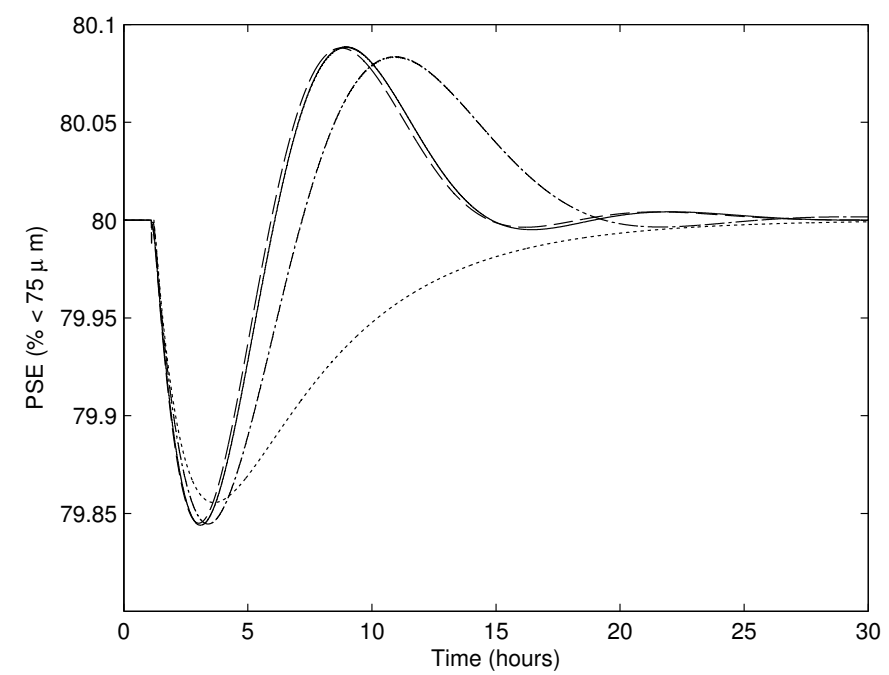

Figure 7: PSE in the presence of a strong external disturbance (change in $\alpha_{r}$ ) with PI (dotted line), DOB (solid line), FO-DOB (dashed line) and BICO-DOB (dash-dot line).

\subsection{External disturbance rejection}

External disturbance rejection is very important in run-of-mine ore milling as a consistent product should be passed to the downstream process while parameters in the milling circuit change continuously. Firstly a change is made in the fraction of rocks in the ore entering the mill $\left(\alpha_{r}\right)$. This parameter changes frequently as the distribution of rocks on the stockpile rarely remains constant. The value of $\alpha_{r}$ is decreased by $20 \%$ at 1 hour and the effect this has on the PSE is shown in Fig. 7. The deviations in the PSE values may seem insignificant on a real plant but here the disturbances are kept relatively small such that the manipulated variables are not driven to their limits. This gives a much clearer comparison of the actual functioning of the controllers as opposed to comparing their constraint handling capabilities.

The ISE as well as the percentage deviation from the nominal value for 
Table 3: Result summary for disturbance rejection and set-point tracking

\begin{tabular}{ccccc} 
& & $\alpha_{r}$-dist. & $\phi_{f}$-dist. & SP-track \\
\hline PI & ISE & 6.314 & 10.864 & 22.439 \\
& $\% O S$ & 0.181 & 0.341 & 0.0 \\
\hline \multirow{2}{*}{ DOB } & ISE & 5.043 & 10.665 & 17.377 \\
& $\% O S$ & 0.194 & 0.351 & 0.201 \\
\hline \multirow{2}{*}{ FO-DOB } & ISE & 5.235 & 10.863 & 17.338 \\
& $\% O S$ & 0.195 & 0.344 & 0.198 \\
\hline \multirow{2}{*}{ BICO-DOB } & ISE & 6.271 & 11.773 & 17.059 \\
& $\% O S$ & 0.194 & 0.336 & 0.177 \\
\hline
\end{tabular}

all 4 control schemes are shown in Table 3 .

Next a change is made in the amount of energy needed for a ton of fines produced $\left(\phi_{f}\right)$. This parameter also changes frequently as the hardness of the ore entering the mill change. The value of $\phi_{f}$ is decreased by $15 \%$ at 1 hour and the effect this has on the PSE is shown in Fig. 8. The ISE as well as the percentage deviation for all 4 control schemes are shown in Table 3.

It is clear from Table 3 that the disturbance observer based control schemes fare the best at disturbance rejection.

\subsection{Set-point tracking in the presence of mismatch}

The set-point tracking capability of each controller in the presence of model-plant mismatch is presented here. Model-plant mismatch is a common occurrence on a run-of-mine ore milling circuit [7] and hinders the performance of most controllers [21].

Some of the uncertainties present in actual milling models have been 


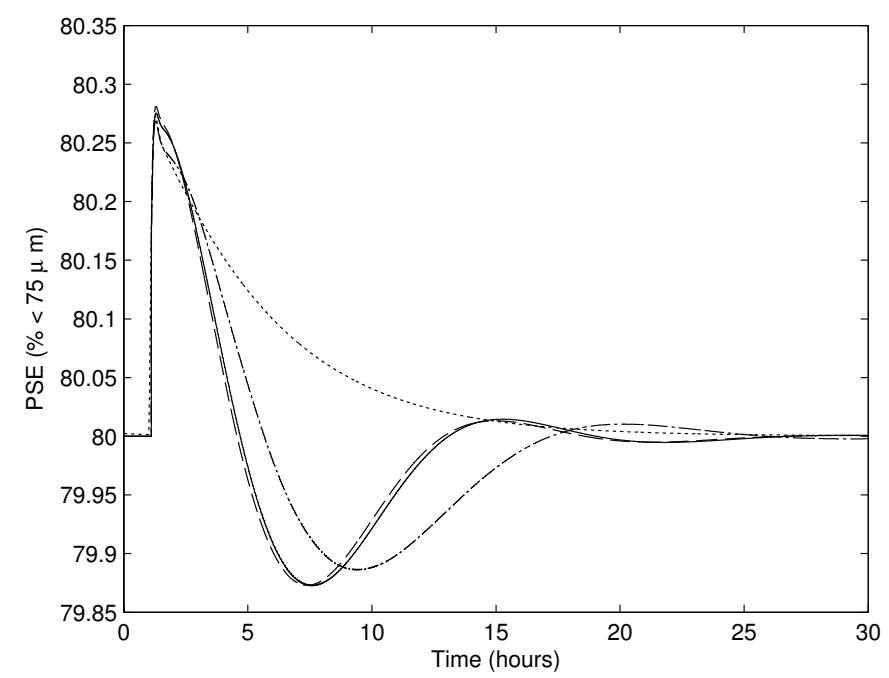

Figure 8: PSE in the presence of a strong external disturbance (change in $\phi_{f}$ ) with PI (dotted line), DOB (solid line), FO-DOB (dashed line) and BICO-DOB (dash-dot line).

quantified in [1] and are known to be severe. For linear models the introduction of model-plant mismatch is as simple as changing the gain, time constant or time delay of the linear model as discussed in [21]. For the nonlinear model however the introduction of model-plant mismatch can only be introduced through changes in the model parameters. These parameter value changes are made before the onset of the simulation.

The parameters whose values are changed are $\alpha_{f}$, which is the fraction of fines in the feed ore, and $\alpha_{r}$, which is the fraction of rocks in feed the ore. The value of $\alpha_{f}$ is increased by $10 \%$ and the value of $\alpha_{r}$ is increased by $10 \%$. Note that $\alpha_{r}$ was used as an external disturbance in Section 5.1 and here it is used to introduce model-plant mismatch. By changing the nominal parameter values before the onset of the simulation, a linearized plant model different to the one used for controller design will result. 


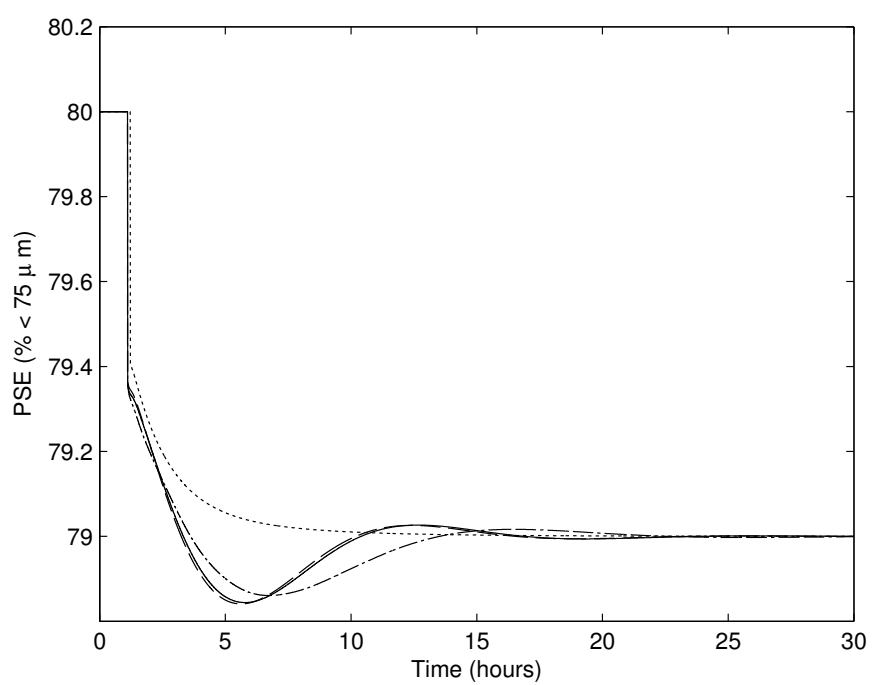

Figure 9: PSE in the presence of MPM with PI (dotted line), DOB (solid line), FO-DOB (dashed line) and BICO-DOB (dash-dot line).

A step change is then made in the set-point for the PSE from $80 \%$ to 79\%. The results are shown in Fig. 9. The summary of the performance of each controller is shown in Table 3.

It is clear from Table 3 that the addition of a disturbance observer to the normal PI controller gives better results than the PI controller alone because of the decrease in the ISE values. The rise times of the responses are also much smaller with the disturbance observer present.

The addition of the integer order DOB results in a substantial decrease in the ISE values shown in Table 3 as also reported by [6]. The order of the FO-DOB is close to the order of the integer order DOB and consequently the results are rather similar. The overall performance is however improved through the smaller value reported for $J$ in (11). The BICO-DOB has poorer disturbance rejection performance than the other two DOB varieties. It does 
however give the best set-point tracking performance. The ease of implementation of a DOB and the substantial performance improvement it delivers makes it an attractive addition to the control loop.

\section{Conclusion}

Using a disturbance observer, it is not only possible to attenuate the external disturbances in a grinding mill circuit, but also reduce the effect of model-plant mismatch as well as uncertainties from internal couplings. This paper contributes a novel fractional order disturbance observer (FO-DOB) for run-of-mine (ROM) ore milling circuit where a fractional order low pass filter $(Q$-filer $)$ is used in the DOB to offer additional tuning freedom to obtain optimal set-point tracking and disturbance rejection performance. The proposed FO-DOB scheme has been tested on a $3 \times 3$ non-linear MIMO plant model, for disturbances that are common and significant as well as under model-plant mismatch which is also usually present, to evaluate the performance gained over the commonly used PI controller and an integer order DOB. The simulation results show that the FO-DOB is a useful additional method to consider when faced with external disturbances, model-plant mismatch and unaccounted coupling effects.

A novel disturbance observer implemented with a BICO low-pass filter is also introduced. The simulation results show that the BICO-DOB gives relatively good performance under the circumstances tested here. It gives the best set-point tracking of all the implementations tested, as well as maintaining good disturbance rejection capabilities. 


\section{Acknowledgements}

Dr. Y. Q. Chen would like to thank the University of Pretoria for partly hosting his sabbatical semester with the University of Pretoria's Department of Electrical, Electronic and Computer Engineering.

\section{Appendix A. Fractional Order Filter Implementation}

The implementation of a fractional order low-pass filter (FO-LPF) and its use in control is presented in [22]. The FO-LPF is of the form

$$
H_{F O L P F}(s)=\left(\frac{1}{\lambda s+1}\right)^{\alpha}
$$

where $\alpha$ is a real number and $\alpha \in(0,1)$. Code available from MATLAB Central ${ }^{1}$ may be used to obtain an implementable finite dimensional transfer function

$$
H_{F O L P F}\left(z^{-1}\right)=\frac{B\left(z^{-1}\right)}{A\left(z^{-1}\right)}=\frac{\sum_{k=0}^{q} b_{k} z^{-k}}{1+\sum_{k=1}^{p} a_{k} z^{-k}}
$$

which is based on the so-called "Impulse response invariant discretization (IRID)."

In order to be able to implement a fractional order filter for which the order is larger than 1, the FO-LPF in the form of (A.1) may be cascaded with an integer order filter of order $n$ as

$$
H(s)=\left(\frac{1}{\lambda_{F O} s+1}\right)^{\alpha}\left(\frac{1}{\lambda_{I O} s+1}\right)^{n}=\left(\frac{1}{\lambda s+1}\right)^{(\alpha+n)}
$$

\footnotetext{
${ }^{1}$ See http://www. mathworks. com/matlabcentral/ fileexchange/21365
} 
if $\lambda_{F O}=\lambda_{I O}$. The order of the overall filter is now $\alpha+n$ where $\alpha \in(0,1)$ and $n \in \mathbb{N}$. When two filters are cascaded to acquire the correct filter order, the bandwidth of the filter will invariably change. In order to acquire a filter of bandwidth $\omega_{B}$ with an order of $\alpha+n$, the filter time constant should be specified to be

$$
\lambda=\frac{\sqrt{2^{1 /(\alpha+n)}-1}}{\omega_{B}} .
$$

\section{Appendix B. BICO Filter Implementation}

The relative degree of the IRID representation of the BICO filter is 0 . Due to this fact the BICO filter should be cascaded with an low-pass filter of order 2 such that the transfer function $Q(s) G_{-}^{-1}(s)$ is realizable (based on the discussion of Sec. 4.1). This is similar to the method used in Appendix A but here the order of the BICO filter is not restricted to be in $(0,1)$.

Code for an impulse response invariant discretization implementation for the BICO filter (similar to that shown in (A.2)) can be found from MATLAB Central ${ }^{2}$.

\section{References}

[1] I.K. Craig and I.M. MacLeod. Specification Framework for Robust Control of a Run-of-Mine ore Milling Circuit. Control Eng. Practice, 3, pp. $621-630,1995$.

\footnotetext{
${ }^{2}$ See http://www.mathworks.com/matlabcentral/fileexchange/28398/
} 
[2] D. Hodouin. Methods for automatic control, observation, and optimization in mineral processing plants. J. Process Control, 21, pp. $211-225$, 2011.

[3] D. Wei and I.K. Craig. Grinding Mill Circuits - A survey of control and economic concerns. Int. J. Miner. Process., 90, pp. 56 - 66, 2009.

[4] M. Bauer and I.K. Craig. Economic assessment of advanced process control - A survey and framework. J. Process Control, 18, pp. 2 - 18, 2008.

[5] M. Ramasamy, S.S. Narayanan and Ch.D.P. Rao. Control of ball mill grinding circuit using model predictive control scheme. J. Process Control, 15, pp. $273-283,2005$.

[6] X.S. Chen, J. Yang, S.H. Li and Q. Li. Disturbance observer based multivariable control of ball mill grinding circuits. J. Process Control, 19, pp. $1205-1213,2009$.

[7] L.E. Olivier and Ian K. Craig. Parameter mismatch detection in a runof-mine ore milling circuit under model predictive control. In: Proc. 18th IFAC World Congress, Milan, Italy, pp. 9929 - 9934, 2011.

[8] L.C. Coetzee, I.K. Craig and E.C. Kerrigan. Robust Nonlinear Model Predictive Control of a Run-of-Mine Ore milling Circuit. IEEE Trans. Control Syst. Technol., 18, pp. 222 - 229, 2010.

[9] L. Ljung. System Identification - Theory for the User. Second Edition. Upper Saddle River, NJ: Prentice Hall, 1999. 
[10] L.C. Coetzee. Robust Nonlinear Model Predictive Control of a Closed Run-of-Mine ore Milling Circuit. Ph.D. thesis, University of Pretoria, 2009 .

[11] L.E. Olivier, I.K. Craig and Y.Q. Chen. Fractional order disturbance observer for a Run-of-Mine ore milling circuit. In: Proc. 10 th IEEE Africon, Zambia, 2011.

[12] D.E. Seborg, T.F. Edgar and D.A. Mellichamp. Process Dynamics and Control. Second Edition. Hoboken, NJ: Wiley, 2004.

[13] G.F. Franklin, J.D. Powell and M.L. Workman. Digital Control of Dynamic Systems. Addison-Wesley, 1990.

[14] Y.Q. Chen, B.M. Vinagre and I. Podlubny. Fractional order disturbance observer for vibration suppression. Nonlinear Dynamics, 38, pp. 355 $367,2004$.

[15] C.J. Kempf and S. Kobayashi. Disturbance observer and feedforward design for a high-speed direct-drive positioning table. IEEE Trans. Control Syst. Technol., 7, pp. 513 - 526, 1999.

[16] Y.Q. Chen, K.K. Ooi, M.Z. Ding, L.L. Tan and K.T. Soh. An Efficient Sensorless Rotational Vibration and Shock Compensator (RVSC) for Hard Disk Drives with Higher TPI. US PTO Published Patent Applications, 2001.

[17] H.D. Zhu, G.H. Zhang and H.H. Shao. Control of the process with inverse response and dead-time based on disturbance observer. In: Proc. 
of the 2005 American Control Conference, Portland, OR, USA, pp. 4826 - 4831, 2005.

[18] S. Skogestad and I. Postlethwaite. Multivariable feedback control : analysis and design. Second Edition. Chichester, England: Wiley, 2005.

[19] W. Li and Y. Hori. Vibration Suppression Using Single Neuron-Based PI fuzzy Controller and Fractional-Order Disturbance Observer. IEEE Trans. Ind. Electron., 54, pp. 117 - 126, 2007.

[20] H.W. Bode. Network Analysis and Feedback Amplifier Design. Van Nostrand, New York, 1945.

[21] A.S. Badwe, R.D. Gudi, R.S. Patwardhan, S.L. Shah and S.C. Patwardhan. Detection of Model-Plant Mismatch in MPC applications. $J$. Process Control, 19, pp. 1305 - 1313, 2009.

[22] C.A. Monje, Y.Q. Chen, B. Vinagre, D. Xue and V. Feliu. Fractional Order Systems and Controls - Fundamentals and Applications. Advances in Industrial Control Series, Springer-Verlag, 2010. 